International Journal of Pure and Applied Mathematics

Volume 84 No. 1 2013, 171-183

ISSN: $1311-8080$ (printed version); ISSN: 1314-3395 (on-line version)

url: http://www.ijpam.eu

doi: http://dx.doi.org/10.12732/ijpam.v84i1.13

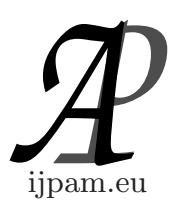

\title{
COMMON FIXED POINT THEOREMS OF COMPATIBLE MAPPINGS IN METRIC SPACES
}

\author{
Jun Kyu Jang ${ }^{1}$, Jun Ki Yun ${ }^{2}$, Nam Jae Bae ${ }^{3}$, Ji Hoo Kim ${ }^{4}$, \\ Dong Min Lee ${ }^{5}$, Shin Min Kang 6 § \\ 1,2,3,4,5 Gyeongnam Science High School \\ Jinju 660-851, KOREA \\ ${ }^{6}$ Department of Mathematics and RINS \\ Gyeongsang National University \\ Jinju, 660-701, KOREA
}

\begin{abstract}
In this paper, we prove some common fixed point theorems of compatible mappings with the generalized contractive mappings in metric spaces and also give some examples to illustrate our main theorems.

These results generalize the results of some authors.
\end{abstract}

AMS Subject Classification: 47H10, 54H25

Key Words: common fixed points, compatible mappings, complete metric spaces, generalized contractive mappings

\section{Introduction}

The most well-known fixed point theorem is so called Banach's fixed point theorem. For an extension of Banach's fixed point theorem, Hardy-Rogers [4], Rhoades [12] and many others introduced a more generalized contractive mappings.

In 1976, Jungck [5] initially proved a common fixed point theorem for commuting mappings, which generalizes the well-known Banach's fixed point

Received: January 17, 2013

(c) 2013 Academic Publications, Ltd.

${ }^{\S}$ Correspondence author

url: www.acadpubl.eu 
theorem. This result has been generalized, extended and improved by many authors (see [2], [3], [6]-[8], [10], [11], [13]-[16]) in various ways.

On the other hand, in 1982, Sessa [14] introduced a generalization of commutativity, which is called the weak commutativity, and proved some common fixed point theorems for weakly commuting mappings which generalize the results of Das-Naik [2].

In 1986, Jungck [6] introduced the concept of the more generalized commutativity, so called compatibility, which is more general than that of weak commutativity. By employing compatible mappings instead of commuting mappings and using four mappings instead of three mappings, Jungck [7] extended the results of Khan-Imdad [10] and Singh-Singh [16].

Further, Cho-Yoo [1] and Kang-Kim [9] proved some fixed point theorems for compatible mappings.

In this paper, we prove some common fixed point theorems of compatible mappings with the generalized contractive mappings in metric spaces and also give some examples to illustrate our main theorems. These results generalize the results of Cho-Yoo [1], Jungck [7] and Kang-Kim [9].

\section{Preliminaries}

The following was introduced by Sessa [14].

Definition 2.1. Let $A$ and $B$ be mappings from a metric space $(X, d)$ into itself. Then $A$ and $B$ are said to be weakly commuting mappings on $X$ if $d(A B x, B A x) \leq d(A x, B x)$ for all $x \in X$.

Clearly, commuting mappings are weakly commuting, but the converse is not necessarily true as in the following example:

Example 2.2. Let $X=[0,1]$ with the Euclidean metric $d$. Define the mappings $A, B: X \rightarrow X$ by

$$
A x=\frac{1}{2} x, \quad B x=\frac{x}{2+x}
$$

for all $x \in X$, respectively.

The following was given by Jungck [6].

Definition 2.3. Let $A$ and $B$ be mappings from a metric space $(X, d)$ into itself. Then $A$ and $B$ are said to be compatible mappings on $X$ if

$$
\lim _{\mathrm{n} \rightarrow \infty} d\left(A B x_{\mathrm{n}}, B A x_{\mathrm{n}}\right)=0
$$


whenever $\left\{x_{\mathrm{n}}\right\}$ is a sequence in $X$ such that $\lim _{\mathrm{n} \rightarrow \infty} A x_{\mathrm{n}}=\lim _{\mathrm{n} \rightarrow \infty} B x_{\mathrm{n}}=t$ for some point $t \in X$.

Obviously, weakly commuting mappings are compatible, but the converse is not necessarily true as in the following example:

Example 2.4. Let $X=(-\infty, \infty)$ with the Euclidean metric $d$. Define the mappings $A, B: X \rightarrow X$ by

$$
A x=x^{3}, \quad B x=2-x
$$

for all $x \in X$, respectively.

We need the following lemmas for our main theorems, which were proved by Jungck [5] and [6].

Lemma 2.5. Let $\left\{y_{\mathrm{n}}\right\}$ be a sequence in a metric space $(X, d)$ satisfying

$$
d\left(y_{\mathrm{n}+1}, y_{\mathrm{n}+2}\right) \leq h d\left(y_{\mathrm{n}}, y_{\mathrm{n}+1}\right)
$$

for $n=1,2, \cdots$, where $0<h<1$. Then $\left\{y_{\mathrm{n}}\right\}$ is a Cauchy sequence in $X$.

Lemma 2.6. Let $A$ and $B$ be compatible mappings from a metric space $(X, d)$ into itself. Suppose that $A t=B t$ for some $t \in X$. Then $d(A B t, B A t)=$ 0 , that is, $A B t=B A t$.

Lemma 2.7. Let $A$ and $B$ be compatible mappings from a metric space $(X, d)$ into itself. Suppose that $\lim _{\mathrm{n} \rightarrow \infty} A x_{\mathrm{n}}=\lim _{\mathrm{n} \rightarrow \infty} B x_{\mathrm{n}}=t$ for some $t \in X$. Then $\lim _{\mathrm{n} \rightarrow \infty} B A x_{\mathrm{n}}=A t$ if $A$ is continuous.

\section{Fixed Point Theorems}

Now, let $A, B, S$ and $T$ be mappings from a metric space $(X, d)$ into itself satisfying the following conditions:

$$
\begin{gathered}
A(X) \subset T(X), \quad B(X) \subset S(X), \\
d(A x, B y) \leq p \max \{d(A x, S x), d(B y, T y), \\
\left.\frac{1}{2}[d(A x, T y)+d(B y, S x)], d(S x, T y)\right\} \\
+q \max \{d(A x, S x), d(B y, T y)\} \\
+r \max \{d(A x, T y), d(B y, S x)\}
\end{gathered}
$$


for all $x, y \in X$, where $0<h=p+q+2 r<1(p, q$ and $r$ are non-negative real numbers). Then, for an arbitrary point $x_{0}$ in $X$, by (3.1), we choose a point $x_{1}$ in $X$ such that $T x_{1}=A x_{0}$ and, for this point $x_{1}$, there exists a point $x_{2}$ in $X$ such that $S x_{2}=B x_{1}$ and so on. Continuing in this manner, we can define a sequence $\left\{y_{\mathrm{n}}\right\}$ in $X$ such that, for $n=0,1,2, \cdots$,

$$
\left\{\begin{array}{l}
y_{2 \mathrm{n}+1}=T x_{2 \mathrm{n}+1}=A x_{2 \mathrm{n}}, \\
y_{2 \mathrm{n}}=S x_{2 \mathrm{n}}=B x_{2 \mathrm{n}-1} .
\end{array}\right.
$$

Lemma 3.1. Let $A, B, S$ and $T$ be mappings from a metric space $(X, d)$ into itself satisfying the conditions (3.1) and (3.2). Then the sequence $\left\{y_{\mathrm{n}}\right\}$ defined by (3.3) is a Cauchy sequence in $X$.

Proof. Let $\left\{y_{\mathrm{n}}\right\}$ be the sequence in $X$ defined by (3.3). From (3.2), we have

$$
\begin{aligned}
& d\left(y_{2 \mathrm{n}+1}, y_{2 \mathrm{n}+2}\right) \\
& =d\left(A x_{2 \mathrm{n}}, B x_{2 \mathrm{n}+1}\right) \\
& \leq p \max \left\{d\left(y_{2 \mathrm{n}}, y_{2 \mathrm{n}+1}\right), d\left(y_{2 \mathrm{n}+1}, y_{2 \mathrm{n}+2}\right),\right. \\
& \quad \frac{1}{2}\left[d\left(y_{2 \mathrm{n}+1}, y_{2 \mathrm{n}+1}\right)+d\left(y_{2 \mathrm{n}}, y_{2 \mathrm{n}+1}\right)+d\left(y_{2 \mathrm{n}+1}, y_{2 \mathrm{n}+2}\right)\right], \\
& \left.\quad d\left(y_{2 \mathrm{n}}, y_{2 \mathrm{n}+1}\right)\right\} \\
& \quad+q \max \left\{d\left(y_{2 \mathrm{n}}, y_{2 \mathrm{n}+1}\right), d\left(y_{2 \mathrm{n}+1}, y_{2 \mathrm{n}+2}\right)\right\} \\
& \quad+r \max \left\{d\left(y_{2 \mathrm{n}+1}, y_{2 \mathrm{n}+1}\right), d\left(y_{2 \mathrm{n}}, y_{2 \mathrm{n}+1}\right)+d\left(y_{2 \mathrm{n}+1}, y_{2 \mathrm{n}+2}\right)\right\},
\end{aligned}
$$

where $0<h=p+q+2 r<1$. In (3.4), if $d\left(y_{2 \mathrm{n}+1}, y_{2 \mathrm{n}+2}\right)>d\left(y_{2 \mathrm{n}}, y_{2 \mathrm{n}+1}\right)$ for some positive integer $n$, then we have

$$
d\left(y_{2 \mathrm{n}+1}, y_{2 \mathrm{n}+2}\right) \leq h d\left(y_{2 \mathrm{n}+1}, y_{2 \mathrm{n}+2}\right),
$$

which is a contradiction. Thus we have

$$
d\left(y_{2 \mathrm{n}+1}, y_{2 \mathrm{n}+2}\right) \leq h d\left(y_{2 \mathrm{n}}, y_{2 \mathrm{n}+1}\right) .
$$

Similarly, we obtain

$$
d\left(y_{2 \mathrm{n}}, y_{2 \mathrm{n}+1}\right) \leq h d\left(y_{2 \mathrm{n}-1}, y_{2 \mathrm{n}}\right) .
$$

It follows from the above facts that

$$
d\left(y_{\mathrm{n}+1}, y_{\mathrm{n}+2}\right) \leq h d\left(y_{\mathrm{n}}, y_{\mathrm{n}+1}\right)
$$

for $n=1,2, \cdots$, where $0<h<1$. By Lemma 2.5, \{yn $\}$ is a Cauchy sequence in $X$. 
Now, we are ready to give our main theorems.

Theorem 3.2. Let $A, B, S$ and $T$ be mappings from a complete metric space $(X, d)$ into itself satisfying the conditions (3.1) and (3.2). Suppose that (3.5) one of $A, B, S$ and $T$ is continuous, (3.6) the pairs $A, S$ and $B, T$ are compatible on $X$.

Then $A, B, S$ and $T$ have a unique common fixed point in $X$.

Proof. Let $\left\{y_{n}\right\}$ be the sequence in $X$ defined by (3.3). By Lemma 3.1, $\left\{y_{\mathrm{n}}\right\}$ is a Cauchy sequence and hence it converges to some point $z \in X$. Consequently, the subsequences $\left\{A x_{2 n}\right\},\left\{S x_{2 n}\right\},\left\{B x_{2 n-1}\right\}$ and $\left\{T x_{2 n-1}\right\}$ of $\left\{y_{n}\right\}$ also converge to the point $z$.

Now, suppose that $S$ is continuous. Since $A$ and $S$ are compatible on $X$, Lemma 2.7 gives that

$$
S^{2} x_{2 \mathrm{n}} \longrightarrow S z, \quad A S x_{2 \mathrm{n}} \longrightarrow S z \quad \text { as } n \rightarrow \infty .
$$

By (3.2), we obtain

$$
\begin{aligned}
& d\left(A S x_{2 \mathrm{n}}, B x_{2 \mathrm{n}-1}\right) \\
& \leq p \max \left\{d\left(A S x_{2 \mathrm{n}}, S^{2} x_{2 \mathrm{n}}\right), d\left(B x_{2 \mathrm{n}-1}, T x_{2 \mathrm{n}-1}\right)\right. \\
& \frac{1}{2}\left[d\left(A S x_{2 \mathrm{n}}, T x_{2 \mathrm{n}-1}\right)+d\left(B x_{2 \mathrm{n}-1}, S^{2} x_{2 \mathrm{n}}\right)\right] \\
& \left.d\left(S^{2} x_{2 \mathrm{n}}, T x_{2 \mathrm{n}-1}\right)\right\} \\
& +q \max \left\{d\left(A S x_{2 \mathrm{n}}, S^{2} x_{2 \mathrm{n}}\right), d\left(B x_{2 \mathrm{n}-1}, T x_{2 \mathrm{n}-1}\right)\right\} \\
& +r \max \left\{d\left(A S x_{2 \mathrm{n}}, T x_{2 \mathrm{n}-1}\right), d\left(B x_{2 \mathrm{n}-1}, S^{2} x_{2 \mathrm{n}}\right)\right\} .
\end{aligned}
$$

Letting $n \rightarrow \infty$, we have

$$
\begin{aligned}
d(S z, z) \leq & p \max \left\{0,0, \frac{1}{2}[d(S z, z)+d(z, S z)], d(S z, z)\right\} \\
& +r d(S z, z)
\end{aligned}
$$

so that $z=S z$. By (3.2), we also obtain

$$
\begin{aligned}
& d\left(A z, B x_{2 \mathrm{n}-1}\right) \\
& \leq p \max \left\{d(A z, S z), d\left(B x_{2 \mathrm{n}-1}, T x_{2 \mathrm{n}-1}\right),\right. \\
& \left.\quad \frac{1}{2}\left[d\left(A z, T x_{2 \mathrm{n}-1}\right)+d\left(B x_{2 \mathrm{n}-1}, S z\right)\right], d\left(S z, T x_{2 \mathrm{n}-1}\right)\right\} \\
& +q \max \left\{d(A z, S z), d\left(B x_{2 \mathrm{n}-1}, T x_{2 \mathrm{n}-1}\right)\right\} \\
& +r \max \left\{d\left(A z, T x_{2 \mathrm{n}-1}\right), d\left(B x_{2 \mathrm{n}-1}, S z\right)\right\} .
\end{aligned}
$$


Letting $n \rightarrow \infty$, we have

$$
\begin{aligned}
& d(A z, z) \\
& \leq p \max \left\{d(A z, S z), 0, \frac{1}{2}[d(A z, z)+d(z, S z)], d(S z, z)\right\} \\
& \quad+q d(A z, S z)+r \max \{d(A z, z), d(z, S z)\}
\end{aligned}
$$

so that $z=A z$. Since $A(X) \subset T(X)$, we have $z \in T(X)$ and hence there exists a point $u \in X$ such that $z=A z=T u$.

$$
\begin{aligned}
& d(z, B u) \\
& =d(A z, B u) \\
& \leq p \max \left\{0, d(B u, T u), \frac{1}{2}[d(A z, T u)+d(B u, z)], d(S z, T u)\right\} \\
& \quad+q d(B u, T u)+r \max \{d(A z, T u), d(B u, z)\}
\end{aligned}
$$

which implies that $z=B u$. Since $B$ and $T$ are compatible on $X$ and $T u=$ $B u=z$, we have $d(T B u, B T u)=0$ by Lemma 2.6 and hence $T z=T B u=$ $B T u=B z$. Moreover, by (3.2), we obtain

$$
\begin{aligned}
& d(z, T z) \\
& =d(A z, B z) \\
& \leq p \max \left\{0, d(B z, T z), \frac{1}{2}[d(z, T z)+d(B z, z)], d(z, T z)\right\} \\
& \quad+q d(B z, T z)+r \max \{d(z, T z), d(B z, z)\},
\end{aligned}
$$

so that $z=T z$. Therefore, $z$ is a common fixed point of $A, B, S$ and $T$. Similarly, we can also complete the proof when $T$ is continuous.

Next, suppose that $A$ is continuous. Since $A$ and $S$ are compatible on $X$, it follows from Lemma 2.7 that

$$
A^{2} x_{2 \mathrm{n}} \longrightarrow A z, \quad S A x_{2 \mathrm{n}} \longrightarrow A z \quad \text { as } n \rightarrow \infty
$$

By (3.2), we have

$$
\begin{aligned}
d\left(A^{2} x_{2 \mathrm{n}},\right. & \left.B x_{2 \mathrm{n}-1}\right) \\
\leq & p \max \left\{d\left(A^{2} x_{2 \mathrm{n}}, S A x_{2 \mathrm{n}}\right), d\left(B x_{2 \mathrm{n}-1}, T x_{2 \mathrm{n}-1}\right)\right. \\
& \frac{1}{2}\left[d\left(A^{2} x_{2 \mathrm{n}}, T x_{2 \mathrm{n}-1}\right)+d\left(B x_{2 \mathrm{n}-1}, S A x_{2 \mathrm{n}}\right)\right] \\
& \left.d\left(S A x_{2 \mathrm{n}}, T x_{2 \mathrm{n}-1}\right)\right\} \\
+ & q \max \left\{d\left(A^{2} x_{2 \mathrm{n}}, S A x_{2 \mathrm{n}}\right), d\left(B x_{2 \mathrm{n}-1}, T x_{2 \mathrm{n}-1}\right)\right\} \\
+ & r \max \left\{d\left(A^{2} x_{2 \mathrm{n}}, T x_{2 \mathrm{n}-1}\right), d\left(B x_{2 \mathrm{n}-1}, S A x_{2 \mathrm{n}}\right)\right\}
\end{aligned}
$$


Letting $n \rightarrow \infty$, we obtain

$$
\begin{aligned}
d(A z, z) \leq & p \max \left\{0,0, \frac{1}{2}[d(A z, z)+d(z, A z)], d(A z, z)\right\} \\
& +r d(A z, z)
\end{aligned}
$$

so that $z=A z$. Hence there exists a point $v \in X$ such that $z=A z=T v$. By (3.2), we also obtain

$$
\begin{aligned}
& d\left(A^{2} x_{2 \mathrm{n}}, B v\right) \\
& \leq p \max \left\{d\left(A^{2} x_{2 \mathrm{n}}, S A x_{2 \mathrm{n}}\right), d(B v, T v),\right. \\
& \left.\quad \frac{1}{2}\left[d\left(A^{2} x_{2 \mathrm{n}}, T v\right)+d\left(B v, S A x_{2 \mathrm{n}}\right)\right], d\left(S A x_{2 \mathrm{n}}, T v\right)\right\} \\
& +q \max \left\{d\left(A^{2} x_{2 \mathrm{n}}, S A x_{2 \mathrm{n}}\right), d(B v, T v)\right\} \\
& +r \max \left\{d\left(A^{2} x_{2 \mathrm{n}}, T v\right), d\left(B v, S A x_{2 \mathrm{n}}\right)\right\} .
\end{aligned}
$$

Letting $n \rightarrow \infty$, we have

$$
\begin{aligned}
& d(z, B v) \\
& \leq p \max \left\{0, d(B v, T v), \frac{1}{2}[d(A z, T v)+d(B v, z)], d(z, T v)\right\} \\
& \quad+q d(B v, T v)+r \max \{d(A z, T v), d(B v, z)\}
\end{aligned}
$$

which implies that $z=B v$. Since $B$ and $T$ are compatible on $X$ and $T v=B v=$ $z$, we have $d(T B v, B T v)=0$ by Lemma 2.6 and hence $T z=T B v=B T v=B z$. Moreover, by (3.2), we have

$$
\begin{aligned}
& d\left(A x_{2 \mathrm{n}}, B z\right) \\
& \leq p \max \left\{d\left(A x_{2 \mathrm{n}}, S x_{2 \mathrm{n}}\right), d(B z, T z)\right. \\
& \left.\quad \frac{1}{2}\left[d\left(A x_{2 \mathrm{n}}, T z\right)+d\left(B z, S x_{2 \mathrm{n}}\right)\right], d\left(S x_{2 \mathrm{n}}, T z\right)\right\} \\
& +q \max \left\{d\left(A x_{2 \mathrm{n}}, S x_{2 \mathrm{n}}\right), d(B z, T z)\right\} \\
& +r \max \left\{d\left(A x_{2 \mathrm{n}}, T z\right), d\left(B z, S x_{2 \mathrm{n}}\right)\right\} .
\end{aligned}
$$

Letting $n \rightarrow \infty$, we obtain

$$
\begin{aligned}
& d(z, B z) \\
& \leq p \max \left\{0, d(B z, T z), \frac{1}{2}[d(z, T z)+d(B z, z)], d(z, T z)\right\} \\
& \quad+q d(B z, T z)+r \max \{d(z, T z), d(B z, z)\},
\end{aligned}
$$


so that $z=B z$. Since $B(X) \subset S(X)$, there exists a point $w \in X$ such that $z=B z=S w$ and so, by $(3.2)$,

$$
\begin{aligned}
& d(A w, z) \\
& =d(A w, B z) \\
& \leq p \max \left\{d(A w, S w), 0, \frac{1}{2}[d(A w, z)+d(z, S w)], d(S w, z)\right\} \\
& \quad+q d(A w, S w)+r \max \{d(A w, z), d(z, S w)\}
\end{aligned}
$$

so that $A w=z$. Since $A$ and $S$ are compatible on $X$ and $A w=S w=z$, we have $d(S A w, A S w)=0$ and hence $S z=S A w=A S w=A z$. Therefore, $z$ is a common fixed point of $A, B, S$ and $T$. Similarly, we can also complete the proof when $B$ is continuous.

Finally, it follows easily from (3.2) that $z$ is a unique common fixed points of $A, B, S$ and $T$. This completes the proof.

The following corollary follows immediately from Theorem 3.2.

Corollary 3.3. Let $A, B, S$ and $T$ be mappings from a complete metric space $(X, d)$ into itself satisfying the conditions (3.1), (3.5) and (3.6). Suppose that

$$
\begin{aligned}
d(A x, B y) \leq & p \max \{d(A x, S x), d(B y, T y), \\
& \left.\frac{1}{2} d(A x, T y), \frac{1}{2} d(B y, S x), d(S x, T y)\right\} \\
& +q \max \{d(A x, S x), d(B y, T y)\} \\
& +r \max \{d(A x, T y), d(B y, S x)\}
\end{aligned}
$$

for all $x, y \in X$, where $0<p+q+2 r<1$. Then $A, B, S$ and $T$ have a unique common fixed point in $X$.

Remark 3.4. If we put $q=0$ in Theorem 3.2 and Corollary 3.3, we obtain the results of Cho-Yoo [1].

Remark 3.5. If we put $q=r=0$ in Theorem 3.2 and Corollary 3.3, we obtain the results of Kang-Kim [9].

Remark 3.6. Theorem 3.2 generalizes the result of Jungck [7] by using any one continuous mapping as opposed to the continuity of both $S$ and $T$ with the generalized contractive mappings (3.2). 


\section{Examples}

In this section, we give some examples to illustrate our main theorems. The following examples were shown by some authors ([1], [3], [7], [9], [15]). Here, we need that the condition (3.2) satisfy in Theorem 3.2.

In the following example, we show the existence of a common fixed point of mappings which are compatible, but they are not weakly commuting and commuting.

Example 4.1. Let $X=[1, \infty)$ with the Euclidean metric $d$. Define the mappings $A, B, S, T: X \rightarrow X$ by

$$
A x=x^{3}, \quad B x=x^{2}, \quad S x=2 x^{6}-1, \quad T x=2 x^{4}-1
$$

for all $x \in X$, respectively. Now, since

$$
\begin{aligned}
d(S x, T y) & =2\left|x^{3}-y^{2}\right|\left|x^{3}+y^{2}\right| \\
& \geq 4 d(A x, B y)
\end{aligned}
$$

for all $x, y \in X$, we obtain

$$
\begin{aligned}
d(A x, B y) \leq & \frac{1}{4} d(S x, T y) \\
\leq & \frac{1}{4} \max \{d(A x, S x), d(B y, T y) \\
& \left.\frac{1}{2}[d(A x, T y)+d(B y, S x)], d(S x, T y)\right\} \\
& +q \max \{d(A x, S x), d(B y, T y)\} \\
& +r \max \{d(A x, T y), d(B y, S x)\}
\end{aligned}
$$

for all $x, y \in X$, where $0 \leq q+2 r<\frac{3}{4}$. Therefore, we see that the hypotheses of Theorem 3.2 except the (weak) commutativity of $A$ and $S$ are satisfied, but $A, B, S$ and $T$ have a unique common fixed point in $X$.

Now, we show that the condition (3.1) is necessary in Theorem 3.2.

Example 4.2. Let $X=[0,1]$ with the Euclidean metric $d$. Define the mappings $A, B, S, T: X \rightarrow X$ by

$$
A x=\left\{\begin{array}{ll}
\frac{1}{4} & \text { if } x=0, \\
\frac{1}{4} x & \text { if } x \neq 0,
\end{array} \quad B x=0, \quad S x=\left\{\begin{array}{ll}
1 & \text { if } x=0, \\
x & \text { if } x \neq 0,
\end{array} \quad T x=x\right.\right.
$$


for all $x \in X$, respectively. Now, we have

$$
\begin{aligned}
d(A x, B y)= & \begin{cases}\frac{1}{4}=\frac{1}{3} d(A x, S x) \quad \text { if } x=0, \\
\frac{1}{4} x=\frac{1}{3} d(A x, S x) \quad \text { if } x \neq 0\end{cases} \\
\leq & \frac{1}{3} \max \{d(A x, S x), d(B y, T y), \\
& \left.\frac{1}{2}[d(A x, T y)+d(B y, S x)], d(S x, T y)\right\} \\
& +q \max \{d(A x, S x), d(B y, T y)\} \\
& +r \max \{d(A x, T y), d(B y, S x)\}
\end{aligned}
$$

for all $x, y \in X$, where $0 \leq q+2 r<\frac{2}{3}$. All the hypotheses of Theorem 3.2 are satisfied except the condition $B(X) \subset S(X)$, but $A$ does not have a fixed point in $X$.

We give an example showing that Theorem 3.2 is no longer true if we do not assume that any one of mappings is continuous.

Example 4.3. Let $X=[0,1]$ with the Euclidean metric $d$. Define the mappings $A, B, S, T: X \rightarrow X$ by

$$
A x=B x=\left\{\begin{array}{ll}
\frac{1}{8} & \text { if } x=0, \\
\frac{1}{8} x & \text { if } x \neq 0,
\end{array} \quad S x=T x= \begin{cases}1 & \text { if } x=0 \\
\frac{1}{2} x & \text { if } x \neq 0\end{cases}\right.
$$

for all $x \in X$, respectively. Now, we obtain

$$
\begin{aligned}
d(A x, A y)= & \begin{cases}0 & \text { if } x=y=0 \\
\frac{1}{8}(1-x)<\frac{1}{4}\left(1-\frac{1}{2} x\right)=\frac{1}{4} d(S y, S x) & \text { if } x>y=0 \\
\frac{1}{8}(1-y)<\frac{1}{4}\left(1-\frac{1}{2} y\right)=\frac{1}{4} d(S x, S y) & \text { if } y>x=0 \\
\frac{1}{8}|x-y|=\frac{1}{4} d(S x, S y) & \text { if } x, y \neq 0\end{cases} \\
\leq & \frac{1}{4} \max \{d(A x, S x), d(A y, S y), \\
& \left.\quad \frac{1}{2}[d(A x, S y)+d(A y, S x)], d(S x, S y)\right\} \\
& +r \max \{d(A x, S x), d(A y, S y)\}
\end{aligned}
$$


for all $x, y \in X$, where $0 \leq q+2 r<\frac{3}{4}$. We find that all the hypotheses of Theorem 3.2 are satisfied except the continuity of $A$ and $S$, but none of mappings $A, S$ has a fixed point in $X$.

We show that the condition of the compatibility is also necessary in Theorem 3.2 .

Example 4.4. Let $X=[0, \infty)$ with the Euclidean metric $d$. Define the mappings $A, B, S, T: X \rightarrow X$ by

$$
A x=B x=\frac{1}{8} x+1, \quad S x=T x=\frac{1}{2} x+1
$$

for all $x \in X$, respectively. Now, we have

$$
\begin{aligned}
d(A x, A y)= & \frac{1}{4} d(S x, S y) \\
\leq & \frac{1}{4} \max \{d(A x, S x), d(A y, S y) \\
& \left.\frac{1}{2}[d(A x, S y)+d(A y, S x)], d(S x, S y)\right\} \\
& +q \max \{d(A x, S x), d(A y, S y)\} \\
& +r \max \{d(A x, S y), d(A y, S x)\}
\end{aligned}
$$

for all $x, y \in X$, where $0 \leq q+2 r<\frac{3}{4}$. We see that all the hypotheses of Theorem 3.2 are satisfied except the compatibility of the pair $A, S$, but $A$ and $S$ don't have a common fixed point in $X$.

Finally, in Remark 3.6, we show the existence of a common fixed point of four mappings by using one continuous mapping as opposed to the continuity of both $S$ and $T$ with the generalized contractive mappings (3.2).

Example 4.5. Let $X=[0,1]$ with the Euclidean metric $d$. Define $A, B$, $S$ and $T: X \rightarrow X$ by

$$
A x=0, \quad B x=\left\{\begin{array}{ll}
\frac{1}{4} & \text { if } x=\frac{1}{2}, \\
\frac{1}{4} x & \text { if } x \neq \frac{1}{2},
\end{array} \quad S x=x, \quad T x= \begin{cases}1 & \text { if } x=\frac{1}{2} \\
x & \text { if } x \neq \frac{1}{2}\end{cases}\right.
$$


for all $x \in X$, respectively. Now, we have

$$
\begin{aligned}
d(A x, B y)= & \left\{\begin{array}{l}
\frac{1}{4}=\frac{1}{3} d(B y, T y) \quad \text { if } y=\frac{1}{2}, \\
\frac{1}{4} y=\frac{1}{3} d(B y, T y) \quad \text { if } y \neq \frac{1}{2},
\end{array}\right. \\
\leq & \frac{1}{3} \max \{d(A x, S x), d(B y, T y), \\
& \left.\frac{1}{2}[d(A x, T y)+d(B y, S x)], d(S x, T y)\right\} \\
& +q \max \{d(A x, S x), d(B y, T y)\} \\
& +r \max \{d(A x, T y), d(B y, S x)\}
\end{aligned}
$$

for all $x, y \in X$, where $0 \leq q+2 r<\frac{2}{3}$. Thus, all the hypotheses of Theorem 3.2 are satisfied. Here, zero is a common fixed point of $A, B, S$ and $T$.

\section{Acknowledgments}

This work was supported by the Korea Foundation for the Advancement of Science and Creativity (KOFAC) grant funded by the Korea government (MEST), 2012.

\section{References}

[1] S.Y. Cho, M.J. Yoo, Common fixed points of generalized contractive mappings, East Asian Math. J., 25 (2009), 1-10.

[2] K.M. Das, K.V. Naik, Common fixed point theorems for commuting maps on a metric space, Proc. Amer. Math. Soc., 77 (1979), 369-373.

[3] B. Fisher, Common fixed points of four mappings, Bull. Inst. Acad. Sin., 11 (1983), 103-113.

[4] G.E. Hardy, T.D. Rogers, A generalization of a fixed point theorem of Reich, Canad. Math. Bull., 16 (1973), 201-206.

[5] G. Jungck, Commuting maps and fixed points, Amer. Math. Monthly, 83 (1976) 261-263. 
[6] G. Jungck, Compatible mappings and common fixed points, Int. J. Math. Math. Sci., 9 (1986), 771-779.

[7] G. Jungck, Compatible mappings and common fixed points (2), Int. J. Math. Math. Sci., 11 (1988), 285-288.

[8] G. Jungck, Common fixed points for commuting and compatible maps on compacta, Proc. Amer. Math. Soc., 103 (1988), 977-983.

[9] S.M. Kang, Y.P. Kim, Common fixed point theorems, Math. Japon., 37 (1992), 1031-1039.

[10] M.S. Khan, M. Imdad, Some common fixed point theorems, Glasnik Mat., 18(38) (1983), 321-326.

[11] S. Park, J.S. Bae, Extensions of a common fixed point theorem of Mier and Keeler, Ark. Math., 19 (1981), 223-228.

[12] B.E. Rhoades, A comparison of various definitions of contractive mappings, Trans. Amer. Math. Soc., 226 (1977), 257-290.

[13] B.E. Rhoades, S. Sessa, M.S. Khan, M.D. Khan, Some fixed point theorems for Hardy-Rogers type mappings, Int. J. Math. Math. Sci., 7 (1984), 75-87.

[14] S. Sessa, On a weak commutativity condition of mappings in fixed point considerations, Publ. Inst. Math., 32(46) (1982), 149-153.

[15] S. Sessa, B.E. Rhoades, M.S. Khan, On common fixed points of compatible mappings in metric and Banach spaces, Int. J. Math. Math. Sci., 11 (1988), 375-392.

[16] S.L. Singh, S.P. Singh, A fixed point theorem, Indian J. Pure Appl. Math., 11 (1980), 1584-1586. 
